\title{
Cytokine-induced killer cell therapy for modulating regulatory $T$ cells in patients with non-small cell lung cancer
}

\author{
BAODAN YU ${ }^{1 *}$, JUNLI WANG $^{2 *}$, CHEN HE $^{3}$, WEI WANG ${ }^{4}$, JIANLI TANG $^{5}$, RUNHUI ZHENG $^{6}$, \\ CHENGZHI ZHOU ${ }^{5}$, HUANHUAN ZHANG ${ }^{5}$, ZHIPING FU ${ }^{7}$, QIASHENG $\mathrm{LI}^{5}$ and $\mathrm{JUN} \mathrm{XU}^{5}$
}

\begin{abstract}
${ }^{1}$ Department of Clinical Laboratory, The First Affiliated Hospital of Guangzhou Medical University, Guangzhou, Guangdong 510120; ${ }^{2}$ Department of Respiration, Shenzhen Hospital of Southern Medical University, Shenzhen, Guangdong 518100; ${ }^{3}$ Department of Respiratory Medicine, The Affiliated Shenzhen Bao'an Hospital of Southern Medical University, Shenzhen, Guangdong 518101; ${ }^{4}$ Department of Medical Oncology, The Affiliated Hospital of Inner Mongolia Medical University, Hohhot, Inner Mongolia 010050; ${ }^{5}$ State Key Laboratory of Respiratory Diseases, Guangzhou Institute of Respiratory Diseases, The First Affiliated Hospital of Guangzhou Medical University, Guangzhou,

Guangdong 510000; ${ }^{6}$ Department of Hematology, The First Affiliated Hospital of Guangzhou Medical University, Guangzhou, Guangdong 510120; ${ }^{7}$ Department of Respiratory Medicine, Jingzhou Central Hospital, The Second Clinical Medical College, Yangtze University, Jingzhou, Hubei 434020, P.R. China
\end{abstract}

Received December 14, 2015; Accepted March 10, 2017

DOI: $10.3892 / \mathrm{etm} .2017 .4562$

\begin{abstract}
Previous studies have reported that regulatory T cells (Tregs), which are physiologically engaged in the maintenance of immunological self-tolerance, have a critical role in the regulation of the antitumor immune response. Targeting Tregs has the potential to augment cancer vaccine approaches. The current study therefore aimed to evaluate the role of cytokine-induced killer (CIK) cell infusion in modulating Tregs in patients with non-small cell lung cancer (NSCLC). A total of 15 patients with advanced NSCLC were treated by an infusion of CIK cells derived from autologous peripheral blood mononuclear cells (PBMCs). By using flow cytometry and liquid chip analysis, subsets of T cells and natural killer (NK) cells in peripheral blood, and plasma cytokine profiles in the treated patients, were analyzed at 2 and 4 weeks after CIK cell infusion. Cytotoxicity of PBMCs $(n=15)$ and NK cells $(n=6)$ isolated from NSCLC patients was evaluated before and after CIK cell therapy. Progression-free survival (PFS) and overall survival (OS) were also assessed. Analysis of the immune cell populations before and after treatment showed a significant increase in NK cells $(\mathrm{P}<0.05)$ concomitant with a significant decrease in
\end{abstract}

Correspondence to: $\mathrm{Dr}$ Jun Xu, State Key Laboratory of Respiratory Diseases, Guangzhou Institute of Respiratory Diseases, The First Affiliated Hospital of Guangzhou Medical University, 1 Kangda Road, Guangzhou, Guangdong 510000, P.R. China E-mail: 10165608@qq.com

${ }^{*}$ Contributed equally

Key words: cytokine-induced killer cells, regulatory $\mathrm{T}$ cells, non-small cell lung cancer
Tregs $(\mathrm{P}<0.01)$ at 2 weeks post-infusion of CIK cells compared with the baseline. NK group 2D receptor (NKG2D) expression on NK cells was also significantly increased at 2 weeks post-infusion compared with the baseline $(\mathrm{P}<0.05)$. There was a positive correlation between $\mathrm{NKG} 2 \mathrm{D}$ expression and the infusion number of CIK cells $(\mathrm{P}<0.05)$. When evaluated at 2 weeks after CIK cell therapy, the cytotoxicity of PBMCs and isolated NK cells was significantly increased compared with the baseline $(\mathrm{P}<0.01$ and $\mathrm{P}<0.05)$. Correspondingly, plasma cytokine profiles showed significant enhancement of the following antitumor cytokines: Interferon (IFN)- $\gamma(\mathrm{P}<0.05)$, IFN- $\gamma$-inducible protein $10(\mathrm{P}<0.01)$, tumor necrosis factor- $\alpha$ $(\mathrm{P}<0.001)$, granulocyte-macrophage colony-stimulating factor $(\mathrm{P}<0.01)$, monocyte chemotactic protein-3 $(\mathrm{P}<0.01)$ and interleukin-21 $(\mathrm{P}<0.05)$ at 2 weeks post-infusion, compared with the baseline. At the same time, the expression of transforming growth factor- $\beta 1$, which is primarily produced by Tregs, was significantly decreased compared with the baseline $(\mathrm{P}<0.05)$. Median PFS and OS in the CIK cell treatment group were significantly increased compared with the control group (PFS, 9.98 vs. 5.44 months, $\mathrm{P}=0.038$; OS, 24.17 vs. 20.19 months, $\mathrm{P}=0.048)$. No severe side-effects were observed during the treatment period. In conclusion, CIK cell therapy was able to suppress Tregs and enhance the antitumor immunity of NK cells in advanced NSCLC patients. Therefore, CIK cell treatment may improve PFS and OS in patients with advanced NSCLC. CIK cell infusion may have therapeutic value for patients with advanced NSCLC, as a treatment that can be combined with chemotherapy and radiotherapy.

\section{Introduction}

Regulatory T cells (Tregs) have a critical function in controlling adaptive immune responses and maintaining self-tolerance. Tregs interact with various immune cell types, some of which 
may be found in the tumor environment $(1,2)$. Thus, Tregs may have an important impact on cancer immune escape. Recruitment of Tregs by tumors has been reported to be one aspect of immune escape (2), so targeting these cells may provide a mechanism by which antitumor immune function can be restored. A variety of agents targeting Tregs have been developed for this reason. These include conventional chemotherapy, which affects Tregs together with other cell types, as well as other strategies aimed at Tregs directly, including the use of specific monoclonal antibodies for CD25 (a depleting antibody), CTLA4 (a blocking antibody), GITR (an agonistic antibody) and OX40 (an agonistic antibody) $(1,3,4)$. However, many current immunotherapeutic strategies that target Tregs may have a negative effect on effector immune cells $(3,5)$, which may result in the therapy being unsuccessful. If immunotherapy is to become a viable option in the treatment of cancer, immunotherapeutic strategies that target Tregs must also have a positive effect on effector cells, shifting the balance in favor of immunity.

Cytokine-induced killer (CIK) cells are heterogeneous in vitro-expanded $\mathrm{T}$ lymphocytes, with a natural killer (NK)/T phenotype and major histocompatibility complex-unrestricted antitumor ability. These biological features of CIK cells make them appealing for adoptive immunotherapy and they have previously displayed encouraging results, which was indicated by the prolonged survival time following their use in tumor therapy (6-8).

Lung cancer is one of the most common malignancies and the leading cause of cancer-related mortality worldwide (9). Approximately $80 \%$ of all lung cancer cases are non-small cell lung cancer (NSCLC) $(10,11)$ and the majority of patients have been diagnosed in the advanced stage (12). At present the primary method for clinical treatment of advanced NSCLC is drug treatment, including chemotherapy and biological therapy (which may involve tumor specific monoclonal antibodies, molecular targeted drugs or antiangiogenic drugs). However, great toxicity is exhibited during chemotherapy and great individual differences of clinical antitumor therapeutic effect with drug treatment. Highly heterogeneous tumor cells could occur in a series of evolutionary changes in the molecular level, subcellular, cell, tissue and organ levels in order to adapt (resistance) or find (transfer) a new living environment under the external pressure (such as chemotherapy, targeted therapy and radiotherapy). Despite developments in cancer treatment and the introduction of novel drugs, advanced lung cancer remains associated with poor prognosis. Adoptive immunotherapy, as a new approach to treat solid tumors, has been reported to hold great potential compared with other traditional treatments (13-20). Adoptive CIK cell transfer, as one type of adoptive immunotherapy, has displayed antitumor effects in various malignant tumor types, including NSCLC (17-21).

Considering the importance of targeting Tregs in cancer immunotherapy, the current study aimed to determine whether CIK cell therapy was able to affect Tregs and effector cells in NSCLC patients. A possible mechanism of adoptive CIK cell therapy was also explored, which has not yet been elucidated.

\section{Materials and methods}

Patient characteristics. A total of 30 patients with stage III-IV NSCLC and similar clinical characteristics, who were hospitalized in the Guangzhou Institute of Respiratory Diseases (Guangzhou, China) between July 2009 and December 2013, with or without CIK cell therapy, were enrolled in this study and randomly assigned to the CIK cell treatment group or non-CIK cell treatment group ( $n=15$ per group). Clinical information, including sex, age, tumor histology and clinical stage are presented in Table I. Patients received chemotherapy before CIK cell immunotherapy.

Inclusion criteria were as follows: i) Pathological or radiographic confirmation of stage III-IV NSCLC tumors; ii) Karnofsky performance status $(22) \geq 50$; iii) life expectancy $\geq 3$ months; and iv) hemogram (hemachrome $>80 \mathrm{~g} / \mathrm{l}$; white blood cell count, $>3 \times 10^{7} / 1$ ), blood urea nitrogen, serum creatinine, alanine aminotransferase, aspartate aminotransferase and alkaline phosphatase were close to normal levels. Rejection criteria were as follows: i) Patients without consent for treatment; ii) patients who had other immune system disorders; and iii) patients who had been treated with steroids within the past 6 weeks.

All patients gave their informed consent prior to inclusion in the study. The study was approved by the Ethics Committee of the First Affiliated Hospital of Guangzhou Medical University (Guangzhou, China).

Preparation of CIK cells and treatment. Peripheral blood mononuclear cells (PBMCs) were collected with a COBE spectra blood cell separator (Terumo BCT, Inc., Lakewood, CO, USA). PBMCs $\left(5.0 \times 10^{6}\right.$ cells $\left./ \mathrm{ml}\right)$ were cultured with TexMACS GMP medium (Miltenyi Biotec GmbH, Bergisch Gladbach, Germany) in the presence of $1.0 \times 10^{6} \mathrm{U} / 1$ human interferon (IFN)- $\gamma$ (Shanghai Fosun Pharmaceutical Group Co., Ltd., Shanghai, China). The cells were incubated for $24 \mathrm{~h}$ in a humidified atmosphere containing $5 \% \mathrm{CO}_{2}$ at $37^{\circ} \mathrm{C}$. Monoclonal antibody against CD3 (MAB100; $50 \mu \mathrm{g} / 1$; R\&D Systems, Inc.,

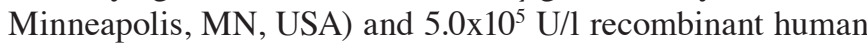
interleukin (IL)-2 (Shandong Quangang Pharmaceutical Co., Ltd., Jinan, China) were added after $24 \mathrm{~h}$ culture at $37^{\circ} \mathrm{C}$. The medium was changed every 3 days with fresh IL-2 supplement. Cells were collected after 2 to 3 weeks of culture. Cell phenotypes of CIK cells were assessed by flow cytometry.

CIK cells were delivered once a day for 3 consecutive days as a course of treatment. The number of cells was between $2 \times 10^{9}$ and $6 \times 10^{9}$ for each infusion.

Trypan blue assay. The cell suspension and the 0.4\% trypan blue solution (Sigma-Aldrich; Merck KGaA, Darmstadt, Germany) were added in equal parts $(100 \mu \mathrm{l})$ and $10 \mu \mathrm{l}$ of this content was transferred to a Neubauer chamber for counting the four lateral quadrants under an inverted light microscope. The viability calculation was made according to the following formula: percentage of viable cells $(\%)=($ live cells/total cells) x 100 . The cells were assessed for viability using the trypan dye-exclusion test and the viability of CIK cells detected by trypan blue was $94.0 \pm 3.6 \%$.

Bacteria, fungi and endotoxin assays. CIK cells were checked twice (the first day of culture and after 2 weeks of culture) for bacteria, fungi or endotoxins. Detection was performed in the Clinical Laboratory of the First Affiliated Hospital of Guangzhou Medical University. 
Table I. Patient characteristics.

\begin{tabular}{lcc}
\hline Characteristic & $\begin{array}{c}\text { Chemotherapy } \\
\text { and CIK cell } \\
\text { therapy (n=15) }\end{array}$ & $\begin{array}{c}\text { Chemotherapy } \\
(\mathrm{n}=15)\end{array}$ \\
\hline Mean age (range) & $59.3(52-68)$ & $59.5(51-73)$ \\
Sex & 8 & 8 \\
$\quad$ Male & 7 & 7 \\
Female & $65 \pm 10.2$ & $62 \pm 9.6$ \\
Karnofsky performance & & \\
status & & 5 \\
Stage & 9 & 10 \\
III & & 10 \\
IV & 10 & 5 \\
Pathology type & 5 & \\
Adenocarcinoma & & \\
Squamous cell carcinoma & & \\
CIK, cytokine-induced killer. & & \\
\hline
\end{tabular}

Bacteria and fungi detection. A BacT/ALERT 3D 240 Microbial Detection System (bioMerieux, Inc., Durham, CA, USA) for detection of bacteria and fungi was used. CIK cell culture medium was collected aseptically and injected into BacT/ALERT SA (258789) and BacT/ALERT SN (258790; both from bioMerieux, Inc.) culture bottles. Bottles were detected by the microbial detection system for bacteria and fungi. The microbial detection system utilized a colorimetric sensor and reflected light to monitor the presence and production of $\mathrm{CO}_{2}$ dissolved in the culture medium. If microorganisms were present in the test sample, $\mathrm{CO}_{2}$ was produced as the organisms metabolize the substrates in the culture medium. When the microorganisms produced $\mathrm{CO}_{2}$, the color of the gas-permeable sensor installed in the bottom of each culture bottle changed from blue-green to yellow. The lighter color resulted in an increase of reflectance units monitored by the system. Bottle reflectance were monitored and recorded by the instrument every $10 \mathrm{~min}$. Over the course of 7 consecutive days, lack of bacteria and fungi growth was regarded as a negative result. All CIK cells infused were negative for bacteria, fungi.

Endotoxin detection. The Limulus Amoebocyte Lysate (LAL) assay was used. CIK cell culture medium was collected aseptically and assayed using Endochrome-K lysate (Charles River Laboratories, Saint-Germain-Nuelles, France) with depyrogenated glass tubes, pipettes and pipette tips. Microplates were analysed using a FLUOstar Omega microplate reader with MARS data analysis software (BMG Labtech, Ortenberg, Germany) and observed at $405 \mathrm{~nm}$ with an optical density value of 0.1 as per manufacturer's recommendations. The control standard endotoxin was used to construct standard curves as described for the kinetic turbidimetric LAL assay. The endotoxin level of CIK cells suspension $<0.5 \mathrm{EU} / \mathrm{ml}$ indicated a negative result. All CIK cells infused were negative for endotoxins.
Isolation of NK cells. Peripheral blood samples $(2-3 \mathrm{ml})$ were used to purify NK cells using a negative selection NK cell isolation kit (Miltenyi Biotec $\mathrm{GmbH}$ ) according to the manufacturer's protocol. Purified NK cells were subsequently cultured in TexMACS GMP medium and used in a cytotoxicity assay.

Cytotoxicity assay. Human lung cancer cell line A549 were purchased from the American Type Culture Collection (Manassas, VA, USA). Effector cells (CIK cells, PBMC or NK cells) were co-cultured with target cells (A549 cells) at effector-to-target (E:T) ratios of 10:1 or 20:1 in TexMACS GMP medium. Target cells without effector cells were used as a negative control. Furthermore, TexMACS GMP medium without any cells was used as a blank control. Cell Counting Kit-8 (Beyotime Institute of Biotechnology, Jiangsu, China) analysis was used to measure the cytotoxicity of effector cells according to the manufacturer's instructions.

Flow cytometry. CD3 FITC (IM1650, $20 \mu 1 /$ test), CD4 FITC/CD8PE/CD3PC5 (6604727, $20 \mu 1 /$ test), CD3 FITC/CD16+56 PE (07735, $20 \mu 1 /$ test), CD16 FITC/CD56 PE/CD3 ECD (A07728, $20 \mu 1 /$ test), NKG2A PE (IM3291U, $20 \mu 1 /$ test), CD3 ECD (A07748, $10 \mu 1 /$ test), CD56 PC5 (A07789, $10 \mu 1 /$ test), NKG2D PE (A08934, $20 \mu 1 /$ test), CD4 FITC (A07750, $20 \mu 1 /$ test), CD127 PE (IM1980, $20 \mu 1 /$ test), CD25PC5 (IM1646, $10 \mu 1 /$ test), IgG1 FITC (A07795, $20 \mu 1 /$ test), IgG1 PE (A07796, $20 \mu 1 /$ test), IgG1 ECD (A07797, $10 \mu \mathrm{l} /$ test), and IgG1 PC5 (A07798, $10 \mu 1 /$ test), were purchased from Immunotech (Beckman Coulter, Inc., Brea, CA, USA) and used for flow cytometry according to the manufacturer's protocol using an EPICS-XL flow cytometer (Beckman Coulter, Inc.). For antibody staining, antibodies were combined with $5 \times 10^{5}$ leucocytes according to the manufacturer's instructions. A total of $100 \mu$ l of the test sample was mixed with antibodies and vortexed gently prior to incubation for $15 \mathrm{~min}$ at room temperature $\left(18-25^{\circ} \mathrm{C}\right)$ away from light. After incubation, a total of $0.5 \mathrm{ml}$ of OptiLyse C (Ref. A11895) was added and vortex immediately for $1 \mathrm{sec}$. Samples were incubated for $10 \mathrm{~min}$ at room temperature $\left(18-25^{\circ} \mathrm{C}\right)$ protected from light. PBS $(0.5 \mathrm{ml})$ was added and the samples were left to incubate for at least $5 \mathrm{~min}$ at room temperature away from light. Subsequently, samples were centrifuges for $5 \mathrm{~min}$ at $300 \mathrm{x} \mathrm{g}$ at room temperature, the supernatant was removed by aspiration and the cell pellet was resuspended in $4 \mathrm{ml}$ PBS. The samples were then centrifuged for $5 \mathrm{~min}$ at $300 \mathrm{x} \mathrm{g}$ at room temperature prior to removal of the supernatant by aspiration. The cell pellet was resuspended in 0.5 or $1 \mathrm{ml}$ of PBS made up with $0.1 \%$ formaldehyde. Samples were analyzed in the flow cytometer (EPICS-XL; Beckman Coulter, Inc.). For evaluation of the immune status of CIK cells, cluster of differentiation $\mathrm{CD}^{+}, \mathrm{CD}^{+}, \mathrm{CD}^{+}, \mathrm{CD}^{+}{ }^{+} \mathrm{CD} 56^{+}$and $\mathrm{CD} 3{ }^{-} \mathrm{CD}(16+56)^{+}$cells were respectively determined. For evaluation of the immune status of NSCLC patients, $\mathrm{CD}^{+}$, $\mathrm{CD}^{+}, \mathrm{CD}^{+}, \mathrm{CD}^{+} / \mathrm{CD}^{+}, \mathrm{CD}^{+} \mathrm{CD}^{2} 6^{+}, \mathrm{CD} 3{ }^{-} \mathrm{CD}(16+56)^{+}$, $\mathrm{CD}^{-} \mathrm{CD}(16+56)^{+} \mathrm{NKG} 2 \mathrm{~A}^{+}, \mathrm{CD} 3{ }^{-} \mathrm{CD}(16+56)^{+} \mathrm{NKG}^{-} \mathrm{D}^{+}$, $\mathrm{CD} 3{ }^{-} \mathrm{CD} 16^{\text {dim }} \mathrm{CD} 56^{\text {high }}, \mathrm{CD} 3{ }^{-} \mathrm{CD} 56^{\mathrm{dim}} \mathrm{CD} 16^{\text {high }}$ cells ratio and $\mathrm{CD} 4{ }^{+} \mathrm{CD} 25^{+} \mathrm{CD} 127^{+}$Treg cells were determined from peripheral blood 1 day before immunotherapy, and at weeks 2 and 4 after immunotherapy. Cells were stained according to the 
manufacturer's directions. Data were analyzed using Expo32 analysis software (V1.2; Beckman Coulter, Inc.).

Evaluation of plasma cytokines. Plasma levels of cytokines, including IFN- $\gamma$, IFN- $\alpha$, IFN- $\gamma$-inducible protein 10 (IP-10), monocyte chemoattractant protein (MCP)-1, macrophage inflammatory protein-1 $\alpha$, tumor necrosis factor (TNF)- $\alpha$, transforming growth factor (TGF)- $\beta, \mathrm{MCP}-3$, granulocyte-macrophage colony-stimulating factor, IL-4, IL-6, IL-8, IL-10, IL-12, IL-15, IL-17, IL-18 and IL-21, were measured in all patients in the CIK cell group before CIK cell therapy, and at weeks 2 and 4 after cell therapy. Bio-Plex Pro magnetic bead-based assays were utilized on the Bio-Plex platform (Bio-Rad Laboratories, Inc., Hercules, CA, USA), according to the manufacturer's instructions. Bio-Plex Manager software, version 6.0 (Bio-Rad Laboratories, Inc.) was used for bead acquisition and analysis.

Therapeutic effect evaluation. Overall survival (OS) was defined as the time from the diagnosis of metastatic NSCLC to patient death. Progression-free survival (PFS) was defined as the time that elapsed from the date of diagnosis to the date of the first event.

Adverse effects. Side-effects of fever, insomnia, anorexia, joint soreness and skin rash were recorded during the experimental period.

Statistical analysis. All data are presented as the mean \pm standard deviation. All statistical analyses were performed using SPSS v21.0 (IBM SPSS, Armonk, NY, USA). T and NK cell subsets, cytokines and cytotoxicity were analyzed with either paired t-tests or non-parametric Wilcoxon signed-rank tests based upon the normality of data. Kaplan-Meier analysis with the log-rank test was used to compare PFS and OS between patient groups. $\mathrm{P}<0.05$ was considered to indicate a statistically significant difference.

\section{Results}

Induction of CIK cells. In order to generate CIK cells in vitro, non-adherent PBMCs were separated and cultured in the presence of IFN- $\gamma$, CD3 monoclonal antibody and IL-2. At day 7 of cell culture, the cell area was $\sim 3$-fold larger than on day 1 . Multiple cells formed clusters and gathered into cell aggregates.

Proliferation and phenotype of PBMCs after CIK cell induction varied between individuals. The total cell number had increased significantly (mean, 8.18-fold) by day 21 after CIK cell induction compared with before treatment $(\mathrm{P}<0.001$; Fig. 1A). The number of $\mathrm{CD}^{+} \mathrm{CD}^{+} 6^{+}$cells had increased significantly (range, 23.28 to 138.55 -fold; mean, 51.56 -fold) by day 21 after CIK cell induction compared with before treatment $\left(\mathrm{P}<0.01\right.$; Fig. 1B). The proportion of $\mathrm{CD}^{+}, \mathrm{CD}^{+} / \mathrm{CD}^{+}$ and $\mathrm{CD}^{+} / \mathrm{CD}^{2} 6^{+}$cells had significantly increased by day 21 compared with before treatment (all $\mathrm{P}<0.01$; Fig. 1C), whereas the proportion of $\mathrm{CD}^{+}{ }^{+} \mathrm{CD} 4^{+} \mathrm{T}$ cells and $\mathrm{CD} 3{ }^{-\mathrm{CD}} 16 / 56^{+}$ NK cells significantly decreased during CIK cell culture $(\mathrm{P}<0.001$ and $\mathrm{P}<0.05$, respectively; Fig. 1C). Viability of CIK cells detected by trypan blue was $>90 \%$ (data not shown). A cytotoxicity assay indicated that the cytotoxicity of PBMCs
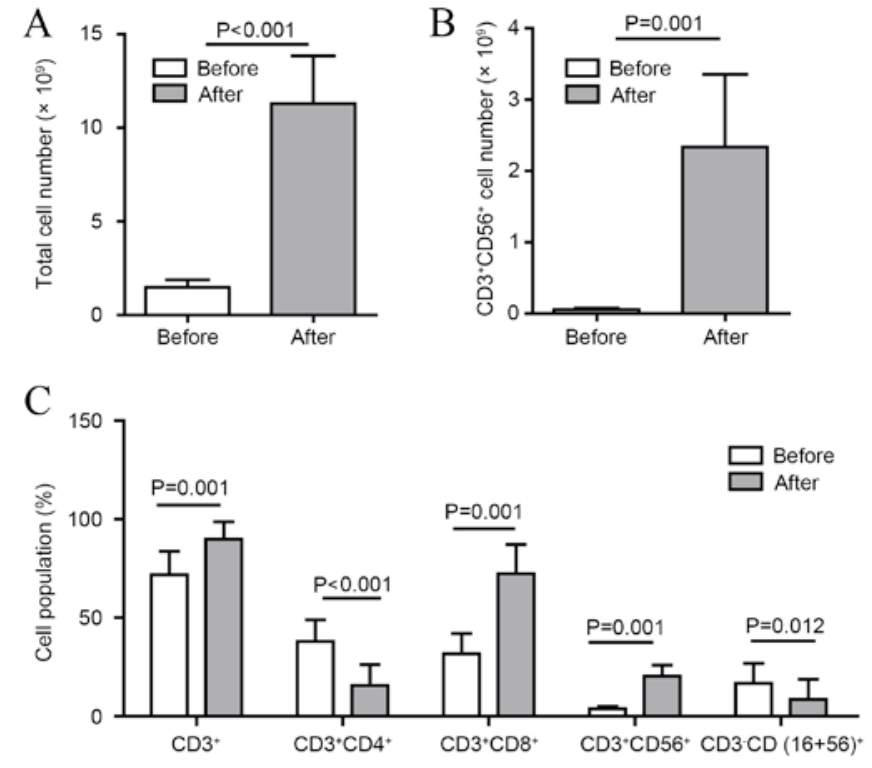

$\mathrm{D}$

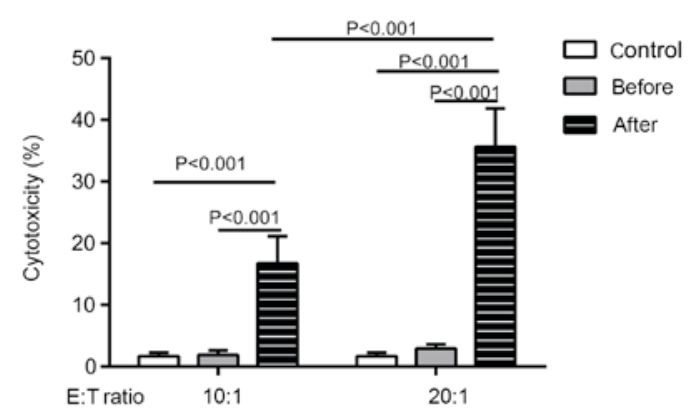

Figure 1. PBMC properties before and after CIK cell induction. (A) Total number of PBMCs, (B) number of $\mathrm{CD}^{+} \mathrm{CD}^{+} 6^{+}$cells and $(\mathrm{C})$ phenotypic analysis of PBMCs before and at day 21 after CIK cell induction $(n=15)$. (D) Cytotoxicity of PBMCs against A549 target cells at E:T ratios of 10:1 and 20:1 before and at day 21 after CIK cell induction $(n=15)$. Data are presented as the mean \pm standard deviation. PBMC, peripheral blood mononuclear cell; CIK, cytokine-induced killer; E:T, effector-to-target.

against A549 cell lines by day 21 after CIK cell induction (E:T ratio, 10:1 or 20:1) was significantly increased compared with that of PBMCs before treatment $(\mathrm{P}<0.001$; Fig. 1D). Cytotoxicity was also significantly increased at an E:T ratio of 20:1 compared with a ratio of 10:1 ( $\mathrm{P}<0.001$; Fig. 1D).

Dynamic changes in Treg and NK cell subsets. In the current study, to investigate changes within Tregs and NK cell subsets, blood samples were collected before CIK cell therapy (baseline) and at 2 and 4 weeks after CIK cell therapy. It was found that the proportion of Tregs was significantly reduced at week 2 compared with the baseline ( 9.99 vs. $9.26 \% ; \mathrm{P}<0.01)$, and remained low at week 4 (Fig. 2A). The percentage of NK cells significantly increased by week 2 compared with the baseline $(\mathrm{P}<0.05$; Fig. $2 \mathrm{~B})$. This was accompanied by a significant increase in NKG2D expression in NK cells at week 2 compared with the baseline (Fig. 3A). The increase in NKG2D expression was positively correlated with the number of CIK cells infused (P<0.05; Fig. 3B). $\mathrm{CD}^{+}, \mathrm{CD}^{+}$, $\mathrm{CD}^{+}, \mathrm{CD}^{+} / \mathrm{CD}^{+}, \mathrm{CD}^{+}{ }^{+} \mathrm{CD} 56^{+}, \mathrm{CD} 3{ }^{-} \mathrm{CD}(16+56)^{+} \mathrm{NKG} \mathrm{A}^{+}$, $\mathrm{CD} 3{ }^{-} \mathrm{CD} 16^{\mathrm{dim}} \mathrm{CD} 56^{\text {high }}$ and $\mathrm{CD} 3{ }^{-} \mathrm{CD} 56^{\mathrm{dim}} \mathrm{CD} 16^{\text {high }}$ cell ratios were also measured but no significant differences were observed during the therapy (data not shown). 
A

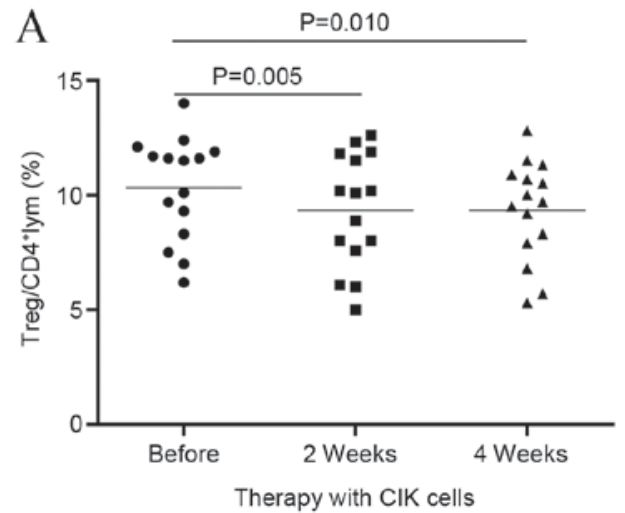

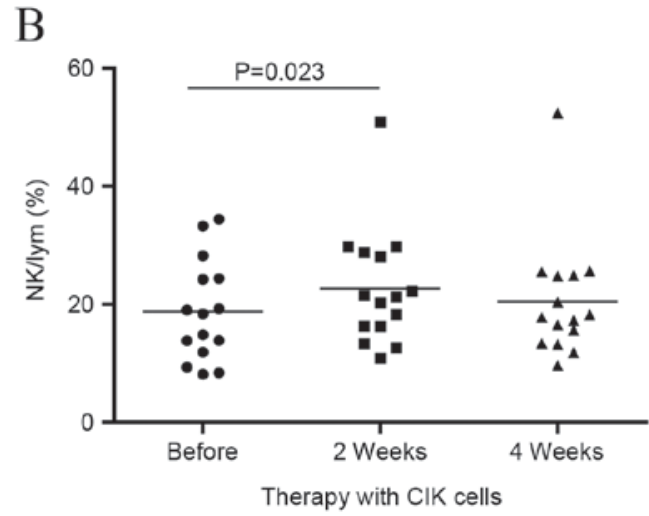

Figure 2. Dynamic phenotypic change of immunocytes in the peripheral blood of non-small cell lung cancer patients before and at 2 or 4 weeks after administration of CIK cells. (A) Percentage of Treg/CD4 ${ }^{+}$cells $(n=15)$. (B) Percentage of NK cells $(n=15)$. NK cell, natural killer cell; CIK, cytokine-induced killer; Treg, regulatory T cell.
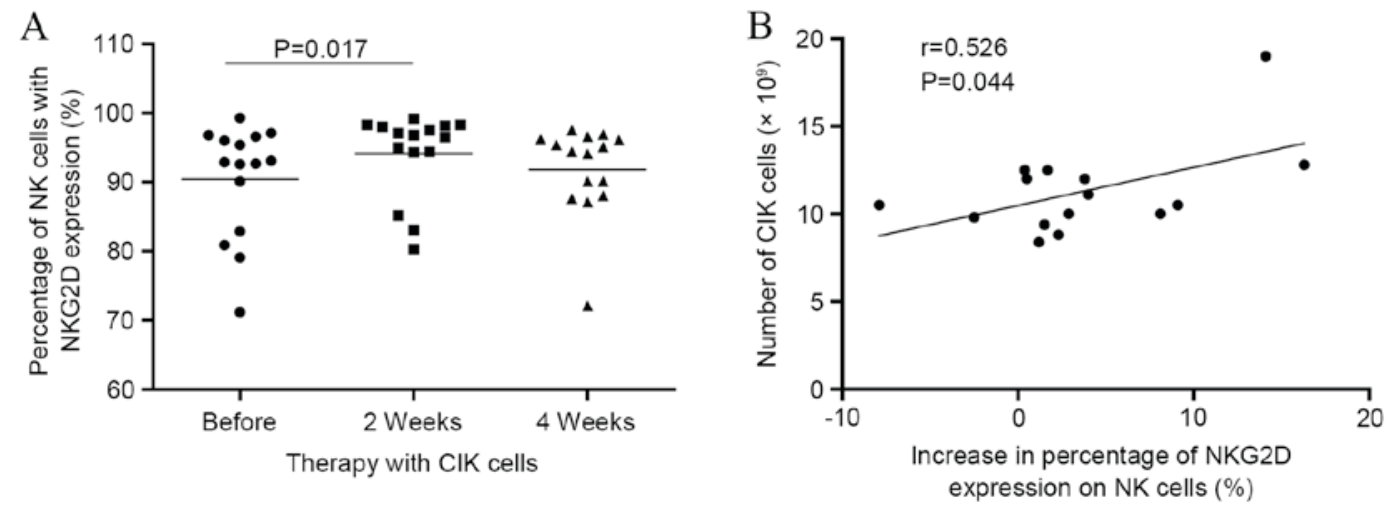

Figure 3. NKG2D expression on NK cells in peripheral blood before and at 2 or 4 weeks after CIK cell therapy. (A) Percentage of NK cells with NKG2D expression ( $\mathrm{n}=15)$. (B) Relationship between the number of CIK cells infused and the percentage of NKG2D expression on NK cells $(\mathrm{n}=15)$. NK cell, natural killer cell; CIK, cytokine-induced killer; NKG2D, NK group 2D receptor.

Cytotoxicity of PBMC or isolated NK cells. Cytotoxicity results with $\mathrm{PBMC}(\mathrm{n}=15)$ and isolated NK cells $(n=6)$ from NSCLC patients before or after CIK cell therapy are shown in Fig. 4. Cytotoxicity of PBMC and isolated NK cells at 2 weeks after CIK cell thwerapy was significantly increased compared with the baseline $(\mathrm{P}<0.05)$. However, there were no significant differences in the cytotoxicity of PBMC or isolated NK cells at 4 weeks compared with the baseline (Fig. 4).

Evaluation of cytokines in the plasma of CIK cell therapy patients. Cytokine levels were evaluated in order to identify those that may be involved in the changes of Tregs and NK cells following CIK cell therapy. There were significant increases in IFN- $\gamma(\mathrm{P}<0.05)$, IP-10 $(\mathrm{P}<0.01)$, TNF- $\alpha(\mathrm{P}<0.001)$, GM-CSF $(\mathrm{P}<0.01), \mathrm{MCP}-3(\mathrm{P}<0.01)$ and IL-21 $(\mathrm{P}<0.05)$ at 2 weeks after CIK cell therapy compared with the baseline (Fig. 5A-F). For all these cytokines, the levels decreased towards baseline levels by week 4 . The opposite trend was observed for plasma TGF- $\beta$ levels, which significantly decreased at week 2 compared with the baseline $(\mathrm{P}<0.05)$ and increased towards baseline levels by week 4 (Fig. 5G). IL-4 and IL-10 were only detected in a small number of samples. For all other cytokines evaluated, no significant differences were found between the baseline and 2 or 4 weeks after therapy (data not shown).

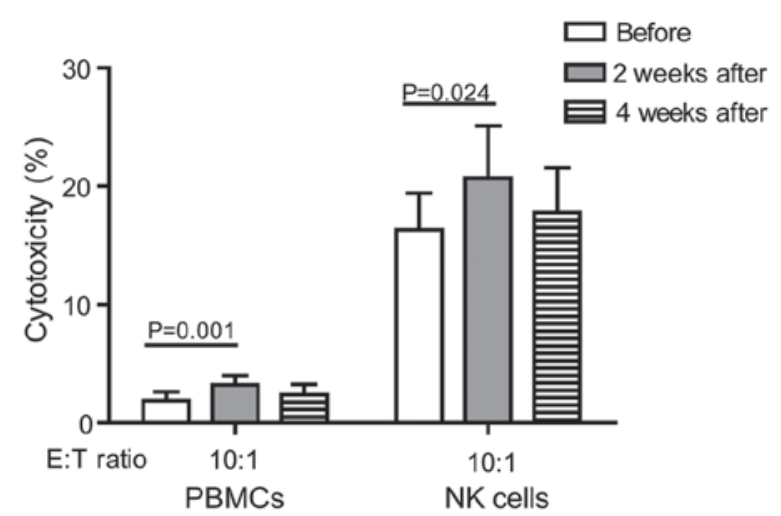

Figure 4. Cytotoxicity of PBMCs $(n=15)$ and NK cells $(n=6)$ against A549 target cells at E:T ratio of 10:1 before and at 2 or 4 weeks after cytokine-induced killer cell induction. Data are presented as the mean \pm standard deviation. PBMCs, peripheral blood mononuclear cells; NK cell, natural killer cell; E:T, effector-to-target.

Evaluation of survival. Median PFS for patients in the CIK cell therapy group and control group were 9.98 months (range, 4.2-43.7 months) and 5.44 months (range, 1.9-27.7 months), respectively. Median OS rates for patients in the CIK cell group and control group were 24.17 months (range, 11.3-51.5 months) and 20.19 months (range, 12.5-44.0 months) 

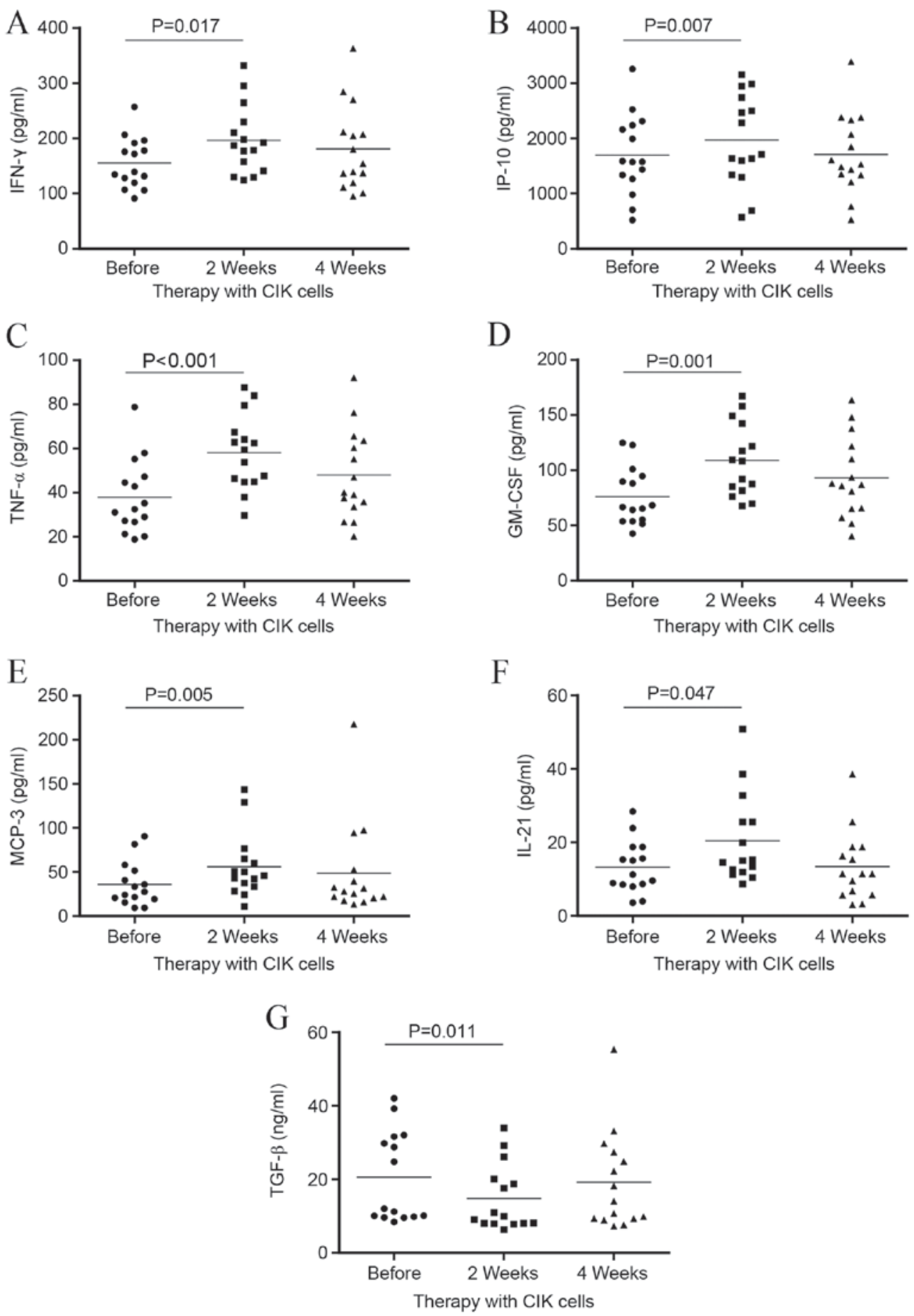

Figure 5. Plasma cytokine profiles of non-small cell lung cancer patients before and at 2 or 4 weeks after cytokine-induced killer cell treatment. Antitumor cytokines (A) IFN- $\gamma$, (B) IP-10, (C) TNF- $\alpha$, (D) GM-CSF, (E) MCP-3, (F) IL-21 and (G) TGF- $\beta 1$ were evaluated (n=15). IFN- $\gamma$, interferon- $\gamma$; IP-10, IFN- $\gamma$-inducible protein 10; TNF- $\alpha$, tumor necrosis factor- $\alpha$; GM-CSF, granulocyte-macrophage colony-stimulating factor; MCP-3, monocyte chemotactic protein-3; IL-21, interleukin-21; TGF- $\beta 1$, transforming growth factor- $\beta 1$; CIK, cytokine-induced killer.

respectively. Median PFS and OS were significantly increased in patients who were given CIK cell therapy plus chemotherapy compared with chemotherapy alone (control group; $\mathrm{P}=0.038$ and $\mathrm{P}=0.048$, respectively; Fig. 6).

Adverse effects. No adverse effects were observed in the CIK cell therapy group, with the exception of 5 patients who experienced transient fever; one case had a temperature of $38.5^{\circ} \mathrm{C}$, whereas the other four cases had temperatures of $<38^{\circ} \mathrm{C}$. All patients with fever recovered within $24 \mathrm{~h}$ without additional treatment.

\section{Discussion}

Previous results indicate that an imbalance between immune suppression and antitumor immunity can promote tumor growth. If immunotherapy is to become a viable option in the treatment of cancer, this imbalance in favor of tumor growth needs to be addressed.

$\mathrm{CD} 4{ }^{+} \mathrm{CD} 25^{+} \mathrm{FOXP} 3{ }^{+}$Tregs account for $5-10 \%$ of all $\mathrm{T}$ lymphocytes in healthy individuals (23). Evidence suggests that Tregs contribute to immune suppression by dampening the 

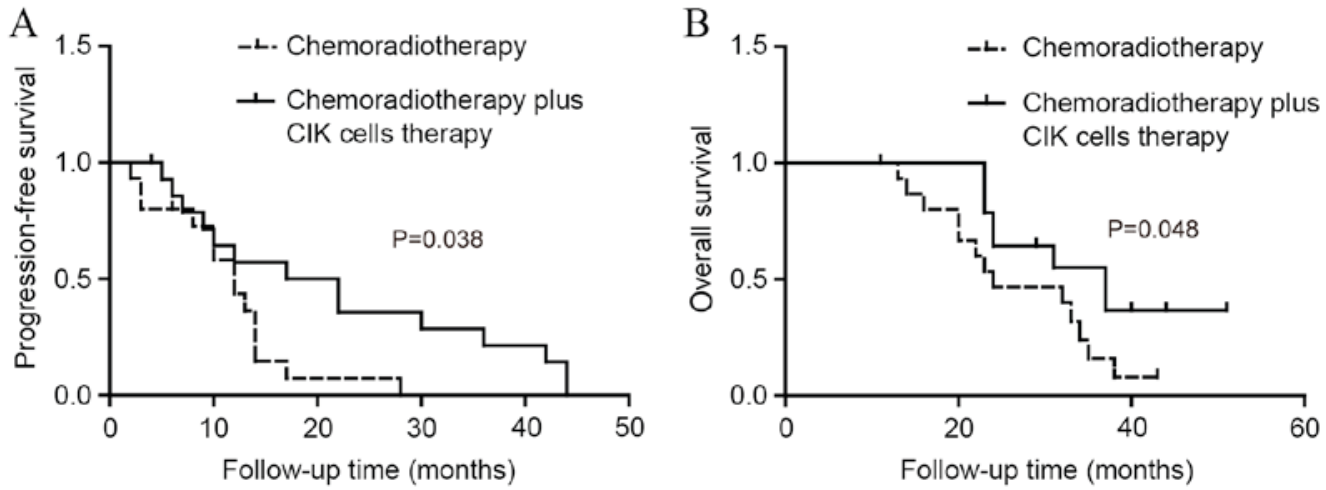

Figure 6. Progression-free survival and overall survival rates in non-small cell lung cancer patients who received routine chemoradiotherapy with or without CIK cell therapy. Survival rates were evaluated using Kaplan-Meier analysis with the log-rank test. (A) Progression-free survival ( $\mathrm{P}=0.038)$. (B) Overall survival $(\mathrm{P}=0.048)$. CIK, cytokine-induced killer.

antitumor immunity elicited by $\mathrm{CD} 4^{+} \mathrm{T}$ cells, $\mathrm{CD} 8^{+} \mathrm{T}$ cells, dendritic and NK cells (24-27). Treg accumulations in tumors and peripheral blood have been linked to unfavorable disease outcomes of tumor invasion, recurrence and shortened survival for many human solid tumors, including hepatocellular carcinoma, ovarian carcinoma, pancreatic ductal carcinoma, cervical cancer, NSCLC and breast cancer (28-33). In these tumors, Tregs suppress antitumor immunity and mediate immune tolerance that favors tumor growth. In this context, Treg could be viewed as a major component of immune evasion from the host immune system and may be used as a marker for poor prognosis. Indeed, reducing Treg function and/or numbers in patients with cancer may result in more effective immune-based therapies, alone or in combination with traditional chemotherapeutics. Numerous preclinical and clinical reports support the notion that elimination of Tregs is crucial to various cancer therapies (34-37).

Previous studies have demonstrated that human peripheral $\mathrm{CD}^{+} \mathrm{CD} 25^{+}$Tregs can be accurately identified and purified using surface expression of CD127, as an alternative to the transcription factor FOXP3 (38-43). Therefore, $\mathrm{CD} 4{ }^{+} \mathrm{CD} 25^{+} \mathrm{CD} 127^{\mathrm{dim}}$ Tregs were used to represent $\mathrm{CD} 4^{+} \mathrm{CD} 25^{+} \mathrm{FOXP}^{+}$Tregs in the current study.

A number of therapeutic approaches are aimed at inhibiting immune suppression within the tumor microenvironment. Specifically, therapies have been developed to deplete major immunosuppressive cell types and a number of direct and indirect methods aimed at depleting Tregs within the tumor microenvironment already exist (44-50). These include specific depletion with monoclonal antibodies (anti-CD25) (49) and depletion with the use of chemotherapeutics, which includes cyclophosphamide (51-54). This remains an area of active research. A major therapeutic challenge remains, however, which is the small number of methods that are able to target Tregs effectively in the clinic.

It is well-established that Tregs are able to affect CIK cells, cytotoxic T cells and NK cells, but data on CIK cell potential activity against Tregs are generally absent, let alone data on the specific effects of CIK cells on Tregs in NSCLC patients. In the current study, it was found that CIK cell infusion was able to downregulate Tregs in the circulation of 15 patients with NSCLC at week 2 post-infusion, and maintained a lower level at 4 weeks post-infusion. Therefore, the present findings suggested that CIK cell infusion is an effective method for targeting Tregs in NSCLC patients, which may have a potential application in therapeutic settings.

The ideal therapeutic strategies that target suppression factors should also have a positive effect on the effector cell compartments, in order to shift the balance in favor of immunity. NK cells are critical for tumor immunity and provide 'spontaneous cytotoxicity' against tumor cells as part of innate immunity. NK cells have the capacity to detect changes in transformed cells even in the absence of inflammatory signals. These changes are recognized by NK cells through their inhibitory and activating receptors (55). NK cells mediate innate immunity and have an important role in cancer immunosurveillance. NK cells are able to recognize tumor cells, due to their decreased HLA expression, and induce lysis before they grow into larger tumor aggregates $(14,56,57)$. According to the current data, $\mathrm{NK}$ cells $\left(\mathrm{CD} 3 \mathrm{CD}^{-} 6^{+} \mathrm{CD} 16^{+}\right)$increased at the same time that Tregs decreased, at 2 weeks after CIK cell therapy.

Expression of activating or inhibitory receptors on NK cells enables self- and non-self-recognition. Depending on the balance between inhibitory and activating signals engaged by ligands expressed on tumor cells, NK cells are triggered to kill or to ignore target cells. NKG2D is an activating receptor expressed on the surface of NK cells, which has an important role in immune responses, including those against tumors $(57,58)$. Data from the current study indicated that expression of activating NK cell receptors, such as NKG2D, increased, whereas expression of inhibitory receptors, such as NKG2A (data not shown), did not vary with CIK cells therapy, suggesting that CIK cell therapy is able to activate NK cells in NSCLC patients. By inducing the upregulation of activating receptors on NK cells, CIK cell therapy may enhance antitumor immunity. A positive correlation was also observed between NKG2D expression and the number of CIK cells infused. This implied that increased CIK cell infusion may contribute to stronger NK activity on tumor cells. Based on previously published data, the alteration of NK cell receptors may be induced by cytokines, including IL-2 $(59,60)$ and IFN (61). Therefore, cytokines of CIK cells may contribute to the enhancement of NKG2D expression in NK cells.

In vitro cytotoxicity assays demonstrated that the antitumor activity of PBMC from 15 NSCLC patients was significantly 
increased at 2 weeks after CIK cell therapy. Cytotoxicity assays of isolated NK cells were similar to those of PBMC assays, although it was only possible to obtain enough p-NK cells to perform this test in 6/15 NSCLC patients. It was indicated that the antitumor efficacy of immune cells, including but not limited to NK cells, from NSCLC was enhanced by CIK cell therapy.

The results of the current study indicated significant increases in plasma IFN- $\gamma$, IP-10, TNF- $\alpha$, GM-CSF, MCP-3 and IL-21 levels in patients at 2 weeks after CIK cell therapy. The general trends were initial increases after treatment was initiated and a subsequently decrease to approximate pre-therapy levels after 4 weeks. Increased levels of cytokines in the serum of patients who received CIK cell infusion suggests the presence of CIK cell-induced T helper 1 (Th1) cell responses. Since Th1 responses seem to be essential in cancer immunotherapy $(62,63)$, this may indicate a therapeutic potential of CIK cell therapy. It was not possible to determine how Tregs and TGF- $\beta$ interact with each other in the blood from the current results. However, previous results suggest that reduction of either Tregs or TGF- $\beta$ may contribute to downregulating harmful tumor suppression, which may favor tumor progression (64-68). In conjunction, serum cytokine profiles suggested that antitumor immunity is enhanced at 2 weeks after CIK cell treatment.

In the current study, infusion of CIK cells was associated with minimal toxicity, and evidence of a disease response was observed. PFS and OS were prolonged in NSCLC patients treated with CIK cells compared with the control group. These results suggest that CIK cell immunotherapy plus chemotherapy for NSCLC has more potential benefits than chemotherapy alone.

To the best of our knowledge, this is the first report to evaluate the role of CIK cell therapy in modulating Tregs in patients with NSCLC. The interaction of CIK cells and regulatory $\mathrm{T}$ cells in the tumor microenvironment requires further research. Improved understanding of the cellular cross-talk between Tregs and CIK cells will aid future therapeutic manipulation of Tregs in cancer treatment.

In conclusion, the current study suggests that CIK cell therapy can reduce Tregs, increase activating NK cells, create an antitumor cytokine environment and contribute to improved PFS and OS in NSCLC patients. These results highlight the potential benefits of combining conventional chemotherapy and CIK cell treatment as an approach for reducing Tregs and improving clinical outcomes for NSCLC patients. Further understanding of the underlying mechanism of CIK cell therapy and its effects on Tregs could enhance future therapeutic approaches.

\section{References}

1. Finotello F and Trajanoski Z: New strategies for cancer immunotherapy: Targeting regulatory T cells. Genome Med 9: 10, 2017.

2. Farashi-Bonab $S$ and Khansari N: Regulatory $T$ cells in cancer patients and their roles in cancer development/progression. MOJ Immunol 1, 00024, 2014

3. Chen C, Chen Z, Chen D, Zhang B, Wang Z and Le H: Suppressive effects of gemcitabine plus cisplatin chemotherapy on regulatory T cells in nonsmall-cell lung cancer. J Int Med Res 43 $180-187,2015$.

4. Sakaguchi S, Miyara M, Costantino CM and Hafler DA: FOXP3 ${ }^{+}$ regulatory $\mathrm{T}$ cells in the human immune system. Nat Rev Immunol 10: 490-500, 2010.
5. Wang Q, Yang L, Xu F, Wang J, An G and Ma Y: Changes of lymphocyte subgroups in non-small cell lung cancer patients before and during chemotherapy. Clin Lab 61: 1343-1351, 2015.

6. Pan K, Guan XX, Li YQ, Zhao JJ, Li JJ, Qiu HJ, Weng DS, Wang QJ, Liu Q, Huang LX, et al: Clinical activity of adjuvant cytokine-induced killer cell immunotherapy in patients with post-mastectomy triple-negative breast cancer. Clin Cancer Res 20: 3003-3011, 2014.

7. Wang M, Shi SB, Qi JL, Tang XY and Tian J: S-1 plus CIK as second-line treatment for advanced pancreatic cancer. Med Oncol 30: 747, 2013.

8. Chen JL, Lao XM, Lin XJ, Xu L, Cui BK, Wang J, Lin GH, Shuang ZY, Mao YZ, Huang X, et al: Adjuvant cytokine-induced killer cell therapy improves disease-free and overall survival in solitary and nonmicrovascular invasive hepatocellular carcinoma after curative resection. Medicine (Baltimore) 95: e2665, 2016.

9. Razzaghi H, Quesnel-Crooks S, Sherman R, Joseph R, Kohler B, Andall-Brereton G, Ivey MA, Edwards BK, Mery L, Gawryszewski V and Saraiya M: Leading causes of cancer mortality-Caribbean region, 2003-2013. MMWR Morb Mortal Wkly Rep 65: 1395-1400, 2016.

10. Tian J and Han S: Role of RRM1 in the treatment and prognosis of advanced non-small cell lung cancer. Zhongguo Fei Ai Za Zhi 18: 381-386, 2015 (In Chinese).

11. Daga A, Ansari A, Patel S, Mirza S, Rawal R and Umrania V: Current drugs and drug targets in non-small cell lung cancer: Limitations and opportunities. Asian Pac J Cancer Prev 16: 4147-4156, 2015.

12. Miller KD, Siegel RL, Lin CC, Mariotto AB, Kramer JL, Rowland JH, Stein KD, Alteri R and Jemal A: Cancer treatment and survivorship statistics, 2016. CA Cancer J Clin 66: 271-289, 2016.

13. Vigneron N: Human tumor antigens and cancer immunotherapy. Biomed Res Int 2015: 948501, 2015.

14. Liu K, Liu X, Peng Z, Sun H, Zhang M, Zhang J, Liu S, Hao L, Lu G, Zheng K, et al: Retargeted human avidin-CAR T cells for adoptive immunotherapy of EGFRvIII expressing gliomas and their evaluation via optical imaging. Oncotarget 6: 23735-23747, 2015.

15. Bigley AB and Simpson RJ: NK cells and exercise: Implications for cancer immunotherapy and survivorship. Discov Med 19: 433-445, 2015.

16. Ascierto ML, Melero I and Ascierto PA: Melanoma: From incurable beast to a curable bet. The success of immunotherapy. Front Oncol 5: 152, 2015.

17. Wang M, Cao JX, Pan JH, Liu YS, Xu BL, Li D, Zhang XY, Li JL, Liu JL, Wang HB and Wang ZX: Adoptive immunotherapy of cytokine-induced killer cell therapy in the treatment of non-small cell lung cancer. PLoS One 9: e112662, 2014.

18. Zhang J, Zhu L, Du H, He X, Yin Y, Gu Y, Liu L, Lu K, Guo R, Liu P and Shu Y: Autologous cytokine-induced killer cell therapy in lung cancer patients: A retrospective study. Biomed Pharmacother 70: 248-252, 2015.

19. Yang B, Lu XC, Zhu HL, Han WD, Wang Y, Fan H, Li SX, Liu Y, Dai HR and Yao SQ: Clinical study of autologous cytokine induced killer cells combined with IL-2 for therapy of elderly patients with B-cell malignant lymphoma. Zhongguo Shi Yan Xue Ye Xue Za Zhi 18: 1244-1249, 2010 (In Chinese).

20. Zhang S, He X, Li X and Ren Y: Clinical study on cytokine induced killer cells therapy to laryngeal cancer after radiotherapy. Lin Chung Er Bi Yan Hou Tou Jing Wai Ke Za Zhi 25: 61-63, 2011 (In Chinese).

21. Li XD, Ji M, Zheng X, Ning ZH, Wu J, Lu B, Wu CP and Jiang JT: Evaluation of tumor response to cytokine-induced killer cells therapy in malignant solid tumors. J Transl Med 12: 215, 2014.

22. Walasek T, Sas-Korczyńska B, Dąbrowski T, Reinfuss M, Jakubowicz J, Blecharz P, Łuczyńska E, Darasz Z and Skotnicki P: Palliative thoracic radiotherapy for patients with advanced non-small cell lung cancer and poor performance status. Lung Cancer 87: 130-135, 2015.

23. Kverneland AH, Streitz M, Geissler E, Hutchinson J, Vogt K, Boës D, Niemann N, Pedersen AE, Schlickeiser S and Sawitzki B: Age and gender leucocytes variances and references values generated using the standardized ONE-Study protocol. Cytometry A 89: 543-564, 2016.

24. Alvarez Arias DA, Kim HJ, Zhou P, Holderried TA, Wang X, Dranoff $\mathrm{G}$ and Cantor $\mathrm{H}$ : Disruption of $\mathrm{CD} 8^{+}$Treg activity results in expansion of $\mathrm{T}$ follicular helper cells and enhanced antitumor immunity. Cancer Immunol Res 2: 207-216, 2014. 
25. Bauer CA, Kim EY, Marangoni F, Carrizosa E, Claudio NM and Mempel TR: Dynamic Treg interactions with intratumoral APCs promote local CTL dysfunction. J Clin Invest 124: 2425-2440, 2014.

26. Guzmán-Flores JM and Portales-Pérez DP: Mechanisms of suppression of regulatory T-cells (Treg). Gac Med Mex 149: 630-638, 2013 (In Spanish)

27. Duan MC, Zhong XN, Liu GN and Wei JR: The Treg/Th17 paradigm in lung cancer. J Immunol Res 2014: 730380, 2014.

28. Perrone G, Ruffini PA, Catalano V, Spino C, Santini D, Muretto P, Spoto C, Zingaretti C, Sisti V, Alessandroni P, et al: Intratumoural FOXP3-positive regulatory $\mathrm{T}$ cells are associated with adverse prognosis in radically resected gastric cancer. Eur J Cancer 44 $1875-1882,2008$

29. Bates GJ, Fox SB, Han C, Leek RD, Garcia JF, Harris AL and Banham AH: Quantification of regulatory T cells enables the identification of high-risk breast cancer patients and those at risk of late relapse. J Clin Oncol 24: 5373-5380, 2006.

30. Mougiakakos D, Choudhury A, Lladser A, Kiessling R and Johansson CC: Regulatory T cells in cancer. Adv Cancer Res 107: $57-117,2010$

31. Nishikawa $\mathrm{H}$ and Sakaguchi S: Regulatory $\mathrm{T}$ cells in tumor immunity. Int J Cancer 127: 759-767, 2010.

32. Curiel TJ, Coukos G, Zou L, Alvarez X, Cheng P, Mottram P, Evdemon-Hogan M, Conejo-Garcia JR, Zhang L, Burow M, et al Specific recruitment of regulatory $\mathrm{T}$ cells in ovarian carcinoma fosters immune privilege and predicts reduced survival. Nat Med 10: 942-949, 2004

33. Bergmann C, Strauss L, Wang Y, Szczepanski MJ, Lang S, Johnson JT and Whiteside TL: T regulatory type 1 cells in squamous cell carcinoma of the head and neck: Mechanisms of suppression and expansion in advanced disease. Clin Cancer Res 14: 3706-3715, 2008.

34. Alizadeh D and Larmonier N: Chemotherapeutic targeting of cancer-induced immunosuppressive cells. Cancer Res 74 2663-2668, 2014.

35. Zhou S, Chen L, Qin J, Li R, Tao H, Zhen Z, Chen H, Chen G, Yang Y, Liu B, et al: Depletion of $\mathrm{CD} 4{ }^{+} \mathrm{CD} 25^{+}$regulatory T cells promotes CCL21-mediated antitumor immunity. PLoS One 8: e73952, 2013

36. Bulliard Y, Jolicoeur R, Zhang J, Dranoff G, Wilson NS and Brogdon JL: OX40 engagement depletes intratumoral Tregs via activating FcgRs, leading to antitumor efficacy. Immunol Cell Biol 92: 475-480, 2014

37. Mattarollo SR, Steegh K, Li M, Duret H, Foong Ngiow S and Smyth MJ: Transient Foxp3(+) regulatory T-cell depletion enhances therapeutic anticancer vaccination targeting the immune-stimulatory properties of NKT cells. Immunol Cell Biol 91: 105-114, 2013.

38. Yu N, Li X, Song W, Li D, Yu D, Zeng X, Li M, Leng X and Li X: CD4(+)CD25 (+)CD127 (low/-) T cells: A more specific Treg population in human peripheral blood. Inflammation 35 1773-1780, 2012

39. Dasgupta A, Mahapatra M and Saxena R: Flow cytometric immunophenotyping of regulatory $\mathrm{T}$ cells in chronic lymphocytic leukemia: Comparative assessment of various markers and use of novel antibody panel with CD127 as alternative to transcription factor FoxP3. Leuk Lymphoma 54: 778-789, 2013.

40. Su H, Longhi MS, Wang P, Vergani D and Ma Y: Human $\mathrm{CD} 4{ }^{+} \mathrm{CD} 25$ (high)CD127 (low/neg) regulatory T cells. Methods Mol Biol 806: 287-299, 2012.

41. Drennan S, Stafford ND, Greenman J and Green VL: Increased frequency and suppressive activity of CD127(low/-) regulatory $\mathrm{T}$ cells in the peripheral circulation of patients with head and neck squamous cell carcinoma are associated with advanced stage and nodal involvement. Immunology 140: 335-343, 2013.

42. Jun C, Ke W, Qingshu L, Ping L, Jun D, Jie L, Bo C and Su M Protective effect of CD4(+)CD25(high)CD127(low) regulatory $\mathrm{T}$ cells in renal ischemia-reperfusion injury. Cell Immunol 289: 106-111, 2014.

43. Marek-Trzonkowska N, Myśliwiec M, Dobyszuk A, Grabowska M, Derkowska I, Juścińska J, Owczuk R, Szadkowska A, Witkowski P, Młynarski W, et al: Therapy of type 1 diabetes with CD4(+)CD25(high)CD127-regulatory T cells prolongs survival of pancreatic islets - results of one year follow-up. Clin Immunol 153 23-30, 2014.

44. Sugiyama D, Nishikawa H, Maeda Y, Nishioka M, Tanemura A, Katayama I, Ezoe S, Kanakura Y, Sato E, Fukumori Y, et al: Anti-CCR4 mAb selectively depletes effector-type FoxP $3^{+} \mathrm{CD} 4^{+}$ regulatory $\mathrm{T}$ cells, evoking antitumor immune responses in humans. Proc Natl Acad Sci USA 110: 17945-17950, 2013.
45. Liakou CI, Kamat A, Tang DN, Chen H, Sun J, Troncoso P, Logothetis C and Sharma P: CTLA-4 blockade increases IFNgamma-producing CD4 ${ }^{+}$ICOShi cells to shift the ratio of effector to regulatory T cells in cancer patients. Proc Natl Acad Sci USA 105: 14987-14992, 2008.

46. Hodi FS, Butler M, Oble DA, Seiden MV, Haluska FG, Kruse A, Macrae S, Nelson M, Canning C, Lowy I, et al: Immunologic and clinical effects of antibody blockade of cytotoxic T lymphocyte-associated antigen 4 in previously vaccinated cancer patients. Proc Natl Acad Sci USA 105: 3005-3010, 2008.

47. Shimizu J, Yamazaki S and Sakaguchi S: Induction of tumor immunity by removing $\mathrm{CD} 25^{+} \mathrm{CD} 4^{+} \mathrm{T}$ cells: A common basis between tumor immunity and autoimmunity. J Immunol 163 : 5211-5218, 1999.

48. Ko K, Yamazaki S, Nakamura K, Nishioka T, Hirota K, Yamaguchi T, Shimizu J, Nomura T, Chiba T and Sakaguchi S: Treatment of advanced tumors with agonistic anti-GITR mAb and its effects on tumor-infiltrating Foxp $3{ }^{+} \mathrm{CD} 25^{+} \mathrm{CD} 4^{+}$regulatory T cells. J Exp Med 202: 885-891, 2005.

49. Onizuka S, Tawara I, Shimizu J, Sakaguchi S, Fujita T and Nakayama E: Tumor rejection by in vivo administration of anti-CD25 (interleukin-2 receptor alpha) monoclonal antibody. Cancer Res 59: 3128-3133, 1999.

50. Mitsui J, Nishikawa H, Muraoka D, Wang L, Noguchi T, Sato E, Kondo S, Allison JP, Sakaguchi S, Old LJ, et al: Two distinct mechanisms of augmented antitumor activity by modulation of immunostimulatory/inhibitory signals. Clin Cancer Res 16: 2781-2791, 2010

51. Dannull J, Su Z, Rizzieri D, Yang BK, Coleman D, Yancey D, Zhang A, Dahm P, Chao N, Gilboa E and Vieweg J: Enhancement of vaccine-mediated antitumor immunity in cancer patients after depletion of regulatory T cells. J Clin Invest 115: 3623-3633, 2005.

52. Tao Q, Chen T, Tao L, Wang H, Pan Y, Xiong S and Zhai Z: IL-15 improves the cytotoxicity of cytokine-induced killer cells against leukemia cells by upregulating $\mathrm{CD}^{+} \mathrm{CD} 56^{+}$cells and downregulating regulatory $\mathrm{T}$ cells as well as IL-35. J Immunother 36: 462-467, 2013.

53. Ganesan AP, Johansson M, Ruffell B, Yagui-Beltrán A, Lau J, Jablons DM and Coussens LM: Tumor-infiltrating regulatory $\mathrm{T}$ cells inhibit endogenous cytotoxic $\mathrm{T}$ cell responses to lung adenocarcinoma. J Immunol 191: 2009-2017, 2013.

54. Walter S, Weinschenk T, Stenzl A, Zdrojowy R, Pluzanska A, Szczylik C, Staehler M, BruggerW, Dietrich PY, Mendrzyk R, etal: Multipeptide immune response to cancer vaccine IMA901 after single-dose cyclophosphamide associates with longer patient survival. Nat Med 18: 1254-1261, 2012.

55. Lanier LL: NK cell recognition. Annu Rev Immunol 23: 225-274, 2005.

56. McDowell KA, Hank JA, DeSantes KB, Capitini CM, Otto M and Sondel PM: NK cell-based immunotherapies in pediatric oncology. J Pediatr Hematol Oncol 37: 79-93, 2015.

57. Crouse J, Xu HC, Lang PA and Oxenius A: NK cells regulating T cell responses: Mechanisms and outcome. Trends Immunol 36: 49-58, 2015.

58. Sentman CL and Meehan KR: NKG2D CARs as cell therapy for cancer. Cancer J 20: 156-159, 2014.

59. Sarkar S, Germeraad WT, Rouschop KM, Steeghs EM, van Gelder M, Bos GM and Wieten L: Hypoxia induced impairment of NK cell cytotoxicity against multiple myeloma can be overcome by IL-2 activation of the NK cells. PLoS One 8: e64835, 2013

60. Hromadnikova I, Pirkova P and Sedlackova L: Influence of in vitro IL-2 or IL-15 alone or in combination with Hsp-70-derived 14-mer peptide (TKD) on the expression of NK cell activatory and inhibitory receptors. Mediators Inflamm 2013: 405295, 2013.

61. Konjevic G, Jurisic V, Jovic V, Vuletic A, Mirjacic Martinovic K, Radenkovic S and Spuzic I: Investigation of NK cell function and their modulation in different malignancies. Immunol Res 52: 139-156, 2012.

62. Luo Y, Henning J and O'Donnell MA: Th1 cytokine-secreting recombinant Mycobacterium bovis bacillus Calmette-Guérin and prospective use in immunotherapy of bladder cancer. Clin Dev Immunol 2011: 728930, 2011.

63. Ito N, Nakamura H, Tanaka Y and Ohgi S: Lung carcinoma: Analysis of T helper type 1 and 2 cells and T cytotoxic type 1 and 2 cells by intracellular cytokine detection with flow cytometry. Cancer 85: 2359-2367, 1999. 
64. Romano S, D'Angelillo A, D'Arrigo P, Staibano S, Greco A, Brunetti A, Scalvenzi M, Bisogni R, Scala I and Romano MF: FKBP51 increases the tumour-promoter potential of TGF-beta. Clin Transl Med 3: 1, 2014.

65. Zhuo C, Xu Y, Ying M, Li Q, Huang L, Li D, Cai S and Li B: FOXP $3^{+}$Tregs: Heterogeneous phenotypes and conflicting impacts on survival outcomes in patients with colorectal cancer. Immunol Res 61: 338-347, 2015.

66. Wilson EB, El-Jawhari JJ, Neilson AL, Hall GD, Melcher AA, Meade JL and Cook GP: Human tumour immune evasion via TGF- $\beta$ blocks NK cell activation but not survival allowing therapeutic restoration of anti-tumour activity. PLoS One 6: e22842, 2011.
67. Itoh $\mathrm{S}$ and Itoh F: Implication of TGF- $\beta$ as a survival factor during tumour development. J Biochem 151: 559-562, 2012.

68. Du Y, Chen X, Lin XQ, Wu W and Huang ZM: Tumor-derived $\mathrm{CD} 4{ }^{+} \mathrm{CD} 25^{+}$Tregs inhibit the maturation and antigen-presenting function of dendritic cells. Asian Pac J Cancer Prev 16: 2665-2669, 2015. 